\title{
G. Matteo Roccati, Pétrarque et Boccace modèles de René d'Anjou
}

\section{Stefania Vignali}

\section{Q OpenEdition}

1 Journals

\section{Edizione digitale}

URL: http://journals.openedition.org/studifrancesi/34396

DOI: 10.4000/studifrancesi.34396

ISSN: 2421-5856

\section{Editore}

Rosenberg \& Sellier

\section{Edizione cartacea}

Data di pubblicazione: 1 novembre 2005

Paginazione: 393

ISSN: 0039-2944

\section{Notizia bibliografica digitale}

Stefania Vignali, «G. Matteo Roccati, Pétrarque et Boccace modèles de René d"Anjou», Studi Francesi [Online], 146 (XLIX | II) | 2005, online dal 30 novembre 2015, consultato il 18 avril 2021. URL: http:// journals.openedition.org/studifrancesi/34396 ; DOI: https://doi.org/10.4000/studifrancesi.34396

Questo documento è stato generato automaticamente il 18 avril 2021.

\section{(c) (i) (9)}

Studi Francesi è distribuita con Licenza Creative Commons Attribuzione - Non commerciale - Non opere derivate 4.0 Internazionale. 
G. Matteo Roccati, Pétrarque et Boccace modèles de René d'Anjou

Stefania Vignali 


\section{NOTIZIA}

G. MATTEO ROCCATI, Pétrarque et Boccace modèles de René d'Anjou, in Favola, Mito e altri saggi di letteratura e filologia in onore di Gianni Mombello, cit., pp. 377-88.

1 In questo contributo allo studio sulla fortuna francese di Petrarca e Boccaccio, l'autore parte da un episodio del Livre du Cuer d'Amours espris di René d'Anjou per mostrare come il poeta si distacchi dalla maniera in cui fino a quel momento i due grandi modelli italiani erano stati accolti nella Francia dell'epoca. L'episodio è quello in cui Cuer nota alcune pietre sepolcrali appartenenti ad amanti celebri o personaggi illustri; aggirandosi nel cimitero, la sua attenzione viene catturata da un gruppo di sei tombe, verosimilmente più illustri di altre. Roccati risponderebbe qui all'esigenza di rendere omaggio e citare i modelli culturali della sua scrittura (nell'ordine Ovidio, Machaut, Boccaccio, Jean de Meung, Petrarca e A. Chartier), soffermandosi in particolar modo sulla descrizione degli elementi caratterizzanti le sepolture dei due illustri italiani. Ma quando si tratta di citare le loro opere, René d'Anjou non cita le opere latine, ma concentra la sua attenzione sulle liriche in italiano, esortando alla lettura in lingua originale.

2 Roccati sottolinea la singolarità di questo atteggiamento nel contesto dell'influenza della cultura italiana in quegli anni e riconsidera la figura di René come mecenate e soprattutto il suo ruolo di precursore per la diffusione della letteratura italiana in volgare, che si generalizzerà solamente nel secolo successivo con le traduzioni dei Trionfi e dei sonetti del Canzoniere.

3 L'autore insiste infine sulla probabile coesistenza di diversi ambienti letterari, precisando la geografia culturale della fortuna di Petrarca e Boccaccio in Francia nella seconda metà del secolo. 